\title{
Diuretic Action of Exogenous Hydrogen Sulfide in Spontaneously Hypertensive Diabetic Rats
}

\author{
Fiaz ud Din Ahmad ${ }^{1 \star}$, Munavvar A Sattar ${ }^{1}$, Hassaan A Rathore ${ }^{1}$, Safia Akhter ${ }^{1}$, \\ Oh Hui Jin ${ }^{1}$ and Edward J Johns ${ }^{2}$ \\ ${ }^{1}$ School of Pharmaceutical Sciences, Universiti Sains Malaysia, Minden, 11800 Penang, Malaysia, ${ }^{2}$ Department of Physiology, \\ Western Gateway Building, University College Cork, Cork, Ireland
}

*For correspondence: Email: fazi2353@yahoo.com; Tel: +60147575494

\begin{abstract}
Purpose: To examine the hypothesis that in hypertensive diabetic rats hydrogen sulphide $\left(H_{2} S\right)$ reduces blood pressure through diuretic action in addition to its vasodilating effect.

Methods: Spontaneously hypertensive rats (SHR) and Wistar-Kyoto (WKY) rats were used. SHR were divided into three groups: SHR (II), SHR diabetic (III), and SHR diabetic NaHS-Treated (IV) with a group of WKY (I) rats serving as normotensive nondiabetic control. Diabetes was produced in two SHR groups using intraperitoneal streptozotocin (STZ). One diabetic group received NaHS, a donor of $\mathrm{H}_{2} \mathrm{~S}$ (56 $\mu M / k g$ i.p.) daily for five weeks. Blood pressure was measured in conscious and anesthetized states in surgically prepared animals. Plasma and urinary $\mathrm{H}_{2} \mathrm{~S}$ levels and electrolytes were measured weekly throughout the 35-day period.

Results: SHR and diabetic SHR had higher blood pressure and lower plasma and urinary $\mathrm{H}_{2} \mathrm{~S}$ levels compared to WKY controls $(p<0.05)$. Moreover, the SHR diabetic group had higher plasma sodium, higher absolute and fractional sodium excretions $(p<0.05)$ but with similar blood pressure compared to SHR controls. NaHS treatment reduced blood pressure and restored $\mathrm{H}_{2} \mathrm{~S}$ and plasma sodium $(p<0.05)$ levels. Moreover, SHR diabetic-NaHS treated group had higher urine output and absolute urinary sodium excretion compared to the untreated SHR diabetic group $(p<0.05)$.

Conclusion: These results suggest a possible diuretic effect of exogenous $\mathrm{H}_{2} \mathrm{~S}$ in spontaneously hypertensive diabetic rats.
\end{abstract}

Keywords: Spontaneously hypertensive rats, Diabetes, Hydrogen sulphide, Diuretic, Sodium excretion, Urine output

Tropical Journal of Pharmaceutical Research is indexed by Science Citation Index (SciSearch), Scopus, International Pharmaceutical Abstract, Chemical Abstracts, Embase, Index Copernicus, EBSCO, African Index Medicus, JournalSeek, Journal Citation Reports/Science Edition, Directory of Open Access Journals (DOAJ), African Journal Online, Bioline International, Open-J-Gate and Pharmacy Abstracts

\section{INTRODUCTION}

It is increasingly apparent that the gaseous molecule $\mathrm{H}_{2} \mathrm{~S}$ can be generated in many types of mammalian cells [1]. Endogenous $\mathrm{H}_{2} \mathrm{~S}$ is accepted as a novel gaseous transmitter with a concentration of $\sim 46 \mu \mathrm{M}$ in rat serum [2]. Recent studies have shown that vascular tissue is capable of generating considerable amounts of $\mathrm{H}_{2} \mathrm{~S}$ [2]. The two pyridoxal phosphate-dependent enzymes, cystathionine beta synthase (CBS) and cystathionine gama lyase (CSE) are responsible for the majority of endogenous $\mathrm{H}_{2} \mathrm{~S}$ production in mammalian tissues and use I-cysteine as the main substrate [1]. The antihypertensive potential of $\mathrm{H}_{2} \mathrm{~S}$ has been investigated and single bolus injections of $\mathrm{NaHS}$, a donor of $\mathrm{H}_{2} \mathrm{~S}$, intravenously produced dose dependent falls in blood pressure [3]. It was suggested that $\mathrm{H}_{2} \mathrm{~S}$ acted on the vascular smooth muscles cells by opening of 
KATP channels producing membrane hyperpolarization resulting in vasorelaxation [2]. Moreover, $\mathrm{H}_{2} \mathrm{~S}$ has been reported to decrease the blood pressure by augmenting the release of endothelium derived hyperpolarizing factor (EDHF) and nitric oxide from the endothelium [4]. $\mathrm{H}_{2} \mathrm{~S}$ has also been implicated in controlling the renal glomerular (vascular) and tubular functions [5]. Spontaneously hypertensive rats (SHR) are a model of essential hypertension. The development of hypertension is linked to altered structural and functional changes in the kidney [6]. The body depends largely on the kidneys for the maintenance of cardiovascular homeostasis. Thus, the kidney is involved in ensuring that there is a balance between the salt and water intake during everyday activity with that excreted in the urine thereby regulating extracellular fluid volume and hence blood pressure [7]. It has been reported in experimental studies that in hypertensive state the induction of diabetes with streptozotocin (STZ) results in accelerated renal injury [8]. It has been proposed that in this pathophysiological state of hypertension and diabetes, there is increased activity of renin angiotensin aldosterone system (RAAS) [9]. This up regulation of RAAS results in increased water and sodium absorption thereby aggravating the hypertension [10].

Together, these previous studies serve to reinforce the view that the kidneys play a pivotal role in regulation of blood pressure and altered renal function is involved in the pathogenesis of essential hypertension. Moreover, the concomitant presence of diabetes further aggravates the already impaired renal function of hypertension. The present study was undertaken to test the hypothesis that the exogenously administered $\mathrm{H}_{2} \mathrm{~S}$ increased the sodium and water excretion in spontaneously hypertensive diabetic rats.

\section{EXPERIMENTAL}

\section{Animals}

Spontaneously hypertensive rats (SHR) and Wistar-Kyoto (WKY) rats weighing $235 \pm 15 \mathrm{~g}$ were obtained from the animal housing and breeding facility of Universiti Sains Malaysia. Rats were allowed to acclimatize for one week before the start of any experimental procedure. All the animals were housed in the same environmental conditions with free access to food (Gold Coin Sdn. Bhd., Penang, Malaysia) and drinking water ad libitum. All procedures and experiments used in this study is in accordance with international guidelines as prescribed by the Canadian Council on the Care and Use of Laboratory Animals in Biomedical Research (1984) and the guidelines of Universiti Sains Malaysia animal ethics committee (USM / Animal Ethics Approval/2010/53, 183).

\section{Experimental protocol}

Spontaneously hypertensive rats were divided at random into three groups $(n=7)$, i.e., SHR (II), SHR diabetic (III) and SHR diabetic treated (IV). The same numbers of identical body weight and age WKY rats served as normotensive control (I). Diabetes was induced in groups III and IV with a single injection of streptozotocin (STZ) (Nova Laboratories, Sdn. Bhd., Selangor, Malaysia). Streptozotocin was freshly prepared in ice cold sodium citrate buffer $(0.1 \mathrm{~mol} / \mathrm{L}, \mathrm{pH} 4.5)$ and injected intraperitoneally at a dose of $40 \mathrm{mg} / \mathrm{kg}$ [11]. The SHR control group of rats (II) was administered with an equal volume of buffer intraperitoneally. After a period of 3 days, a drop of blood was obtained by nicking the tail on overnight fasted rats and glucose concentrations in $\mathrm{mg} / \mathrm{dl}$ were measured using a glucometer (GlucoSure plus, Apex Biotechnology Corp., Hsinchu, Taiwan) to determine the degree of hyperglycemia. Only animals demonstrating a fasting blood glucose above or equal to 350 $\mathrm{mg} / \mathrm{dl}$ were included for the further study [12]. After the affirmation of diabetes, a donor of exogenous $\mathrm{H}_{2} \mathrm{~S}$, Sodium hydrosulfide ( $\mathrm{NaHS}$ ) (Sigma Aldrich, Malaysia), at dose of $56 \mu \mathrm{mol} / \mathrm{kg}$ [13] was injected intraperitoneally to group IV rats daily for five weeks. Groups II and III served as SHR and SHR diabetic control, respectively, and did not receive any treatment.

\section{Blood pressure measurement}

The indirect measurement of the blood pressure was made by the tail cuff method using the Model 29 pulse amplifier and Model 20NW cuff pump coupled to a computerized data acquisition system (PowerLabß, ADInstruments, Sydney, Australia) on days 0 and 21. At day 34 of the study, surgically prepared animals were subjected to the measurement of an invasive blood pressure under ketamine and xylazine anesthesia.

\section{Surgical procedure for invasive blood pressure measurement}

All the rats were fasted overnight before the acute experiment and anaesthetized using a cocktail of ketamine (llium, Australia) $80 \mathrm{mg} / \mathrm{kg}$ and xylazine (llium, Australia) $10 \mathrm{mg} / \mathrm{kg}$ i.p. [14], and were add-on intravenously with ketamine at 
a dose of $50 \mathrm{mg} / \mathrm{kg}$ if required. Immediately after the anesthesia, tracheotomy was performed to maintain a clear air way using an endotracheal cannula (PP 240, Portex Ltd, Kent, UK). The left jugular vein was catheterized with PP 50 tubing (Portex Ltd, Kent, UK) to allow the infusion of supplementary anesthesia. The right carotid artery was cannulated with PP 50 tubing (Portex Ltd Kent, UK) and the cannula was advanced up to the aortic arch and was connected to a pressure transducer (P23 ID Gould, Statham Instruments, UK) linked to a data acquisition system (PowerLab®), ADInstruments, Sydney, Australia) through a Quad Amp (ADInstruments, Australia) using chart Pro (V.5.5) software. The animals were allowed to stabilize for one hour upon completion of above surgical procedure. After the stabilization period mean arterial pressure, systolic blood pressure, pulse pressure and heart rate were recorded over a $30 \mathrm{~min}$ period and averaged.

\section{Metabolic study and collection of plasma}

Water intake and urine output data was collected in all the groups of animals involved in the present study on days 0,21 and 34 of 35 days duration study. Rats were placed in metabolic cages for $24 \mathrm{~h}$. Water intake and urine output were measured in $\mathrm{ml} / 24 \mathrm{~h}$. Similarly, blood samples were obtained on days 0,21 and 34 into a pre-cooled heparinized Eppendorf tube and plasma was obtained by centrifugation of the blood sample at $2500 \mathrm{rpm}$ for five $\mathrm{min}$. The

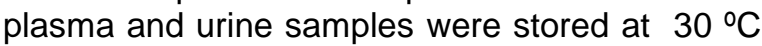
for further analysis [15].

\section{Drugs/chemicals}

NaHS, zinc acetate, N,N-2dimethyl-pphenylenediamine sulfate, $\mathrm{FeCl}_{3}$, trichloroacetic acid, $\mathrm{NaOH}$ and picric acid of analytical grade were obtained from Sigma (Sigma Aldrich, Malaysia).

\section{Measurement of plasma and urinary $\mathrm{H}_{2} \mathrm{~S}$ levels}

Plasma and urinary $\mathrm{H}_{2} \mathrm{~S}$ levels were measured spectrophotometrically [13]. In brief, $100 \mu \mathrm{l}$ of aliquots of the samples were mixed with $50 \mu$ of distilled water in micro-centrifuge tubes already containing $300 \mu \mathrm{l}$ of zinc acetate $(1 \% \mathrm{w} / \mathrm{v})$ to entrap $\mathrm{H}_{2} \mathrm{~S}$. The reaction was terminated after 5 min by adding $200 \mu \mathrm{l}$ of N,N-2dimethyl-pphenylenediamine sulfate $(20 \mathrm{mM}$ in $7.2 \mathrm{M} \mathrm{HCl})$ and instantly followed by addition of $200 \mu \mathrm{l}$ of $\mathrm{FeCl}_{3}(30 \mathrm{mM}$ in $1.2 \mathrm{M} \mathrm{HCl})$. The mixture was incubated in dark for $20 \mathrm{~min}$. Protein from the samples (even a trace amount), was precipitated by using $150 \mu \mathrm{l}$ of trichloroacetic acid (10\% w/v). The resultant mixture was centrifuged at 10,000 rpm for $10 \mathrm{~min}$. The absorbance of the supernatant was measured at $670 \mathrm{~nm}$ using a 96-well plate reader (Bio-Tek instruments, INC, USA). All samples were assayed in replicas. Finally, $\mathrm{H}_{2} \mathrm{~S}$ concentration in the plasma or urine was determined against the calibration curve of standard $\mathrm{H}_{2} \mathrm{~S}$ solutions (NaHS: 3.125-100 $\mu \mathrm{M}$ ). All the above used chemicals were obtained from Sigma (Sigma Aldrich, Malaysia).

\section{Measurement of plasma and urinary sodium/creatinine}

Sodium concentration in plasma and urine were measured by using a flame photometer (Jenway Ltd., Felsted.UK). Absolute urinary $\mathrm{Na}^{+}$excretion was expressed in $\mathrm{mmol} / \mathrm{hour} / 100 \mathrm{~g}$ body weight. Plasma and urinary creatinine concentrations were measured spectrophotometrically (Jaffe's reaction) in order to calculate the fractional $\mathrm{Na}^{+}$ excretion. $\mathrm{FE}_{\mathrm{Na}}(\%)$ was computed using $\mathrm{Eq} 1$.

$\mathrm{FE}_{\mathrm{x}}(\%)=\left\{\mathrm{Na}^{+} \mathrm{u}(\mathrm{mmol} / \mathrm{L}) \times \mathrm{C}_{\mathrm{p}}(\mathrm{mg} / \mathrm{dl}) \times\right.$ $100\} /\left\{\mathrm{Na}^{+}{ }_{p}(\mathrm{mmol} / \mathrm{L}) \times \mathrm{C}_{\mathrm{U}}(\mathrm{mg} / \mathrm{dl})\right\} \ldots \ldots \ldots \ldots(1)$

where $\mathrm{Na}^{+} U$ is urinary $\mathrm{Na}^{+}, \mathrm{C}_{p}$ is plasma creatinine, $\mathrm{Na}_{p}^{+}$is plasma $\mathrm{Na}^{+}$and $\mathrm{C}_{U}$ is urinary creatinine concentration.

\section{Statistical analysis}

All the data were expressed as means \pm SEM. Statistical significance was set at $p<0.05$. Statistical analysis was performed using one way analysis of variances (ANOVA) followed by Bonferroni's/Dunn all means post hoc test for the pair wise comparison between the groups in respective days using the statistical package, Superanova (Abacus Inc, CA, USA).

\section{RESULTS}

A single dose of intraperitoneal STZ injection successfully induced diabetes in SHR as evident from Table 1, whereby significant hyperglycemia had developed ( $p<0.05)$. There was also a decrease in body weight in SHR diabetic groups as compared to the non diabetic SHR control. The SHR diabetic NaHS-treated group remained hyperglycemic and continued to lose weight regardless of the treatment $(p<0.05)$. Moreover, the SHR diabetic group had higher plasma creatinine (Table 2) compared to SHR control and with administration of $\mathrm{NaHS}$, the treated rats exhibited decreased plasma creatinine compared to SHR diabetic control $(p<0.05)$. Furthermore, SHR diabetic rats had higher urine output volume 
and water intake when compared to the SHR non diabetic group on all three time points $(p<0.05)$. Moreover, the SHR diabetic-NaHS treated group had increased urine output and water intake on day 34 as compared to SHR diabetic group $(p<$ 0.05 ; Figure 1 and 2).

Table 1: Effect of exogenous $\mathrm{H}_{2} \mathrm{~S}$ on blood glucose and bodyweight in WKY, SHR, SHR diabetic and SHR diabetic NaHS-Treated groups

\begin{tabular}{|c|c|c|c|c|}
\hline \multirow[b]{2}{*}{ Parameter } & \multirow[b]{2}{*}{ Group } & \multicolumn{3}{|c|}{ Observation } \\
\hline & & Day 0 & Day 21 & Day 34 \\
\hline \multirow[t]{3}{*}{ Blood glucose $(\mathrm{mg} / \mathrm{dl})$} & I & $87.4 \pm 1.6$ & $86.0 \pm 2.5$ & $89.4 \pm 3.0$ \\
\hline & II & $88.5 \pm 2.4$ & $87.2 \pm 1.5$ & $89.2 \pm 3.0$ \\
\hline & $\begin{array}{l}\text { III } \\
\text { IV }\end{array}$ & $\begin{array}{c}395.0 \pm 9.7^{\mathrm{ab}} \\
380.1 \pm 6.7^{\mathrm{a}}\end{array}$ & $\begin{array}{c}391.0 \pm 6.7^{\mathrm{a} b} \\
386.0 \pm 8.3^{\mathrm{a}}\end{array}$ & $\begin{array}{c}388.0 \pm 6.0^{\mathrm{a} b} \\
383.0 \pm 6.8^{\mathrm{a}}\end{array}$ \\
\hline \multirow[t]{3}{*}{ Body weight (g) } & $\begin{array}{l}\text { I } \\
\text { II }\end{array}$ & $\begin{array}{l}243.0 \pm 3.1 \\
238.5 \pm 2.6\end{array}$ & $\begin{array}{l}268.4 \pm 2.3 \\
278.1 \pm 3.1\end{array}$ & $\begin{array}{l}301.3 \pm 2.7 \\
302.1 \pm 3.3\end{array}$ \\
\hline & III & $245.0 \pm 3.8$ & $225.1 \pm 2.1^{\mathrm{ab}}$ & $207.3 \pm 2.2^{\mathrm{ab}}$ \\
\hline & IV & $244.0 \pm 2.9$ & $222.0 \pm 2.1^{\mathrm{a}}$ & $201.0 \pm 3.0^{\mathrm{a}}$ \\
\hline
\end{tabular}

Note: Group I= WKY control, Group II = SHR, Group III = SHR diabetic and Group IV = SHR diabetic NaHStreated; ${ }^{a} p<0.05$ versus WKY on respective days; ${ }^{b} p<0.05$ versus SHR on respective days; ${ }^{c} p<0.05$ versus SHR diabetic on respective days

Table 2: Effect of exogenous $\mathrm{H}_{2} \mathrm{~S}$ on plasma and urinary creatinine in WKY, SHR, SHR diabetic and SHR diabetic NaHS-Treated groups

\begin{tabular}{lcccc}
\hline & & \multicolumn{3}{c}{ Observation } \\
\cline { 3 - 4 } Parameter & Group & Day 0 & Day 21 & Day 34 \\
\hline Plasma Cr.(mg/dl) & I & $0.85 \pm 0.02$ & $0.90 \pm 0.03$ & $0.93 \pm 0.01$ \\
& II & $0.87 \pm 0.03$ & $0.89 \pm 0.04$ & $0.89 \pm 0.05$ \\
& III & $1.13 \pm 0.05^{\mathrm{ab}}$ & $1.28 \pm 0.05^{\mathrm{ab}}$ & $1.36 \pm 0.07^{\mathrm{ab}}$ \\
& IV & $1.10 \pm 0.03^{\mathrm{a}}$ & $1.07 \pm 0.06^{\mathrm{c}}$ & $1.04 \pm 0.04^{\mathrm{c}}$ \\
Urinary Cr. (mg/dl) & & $151.0 \pm 2.0$ & $155.9 \pm 3.0$ & $157.0 \pm 1.1$ \\
& I & $100.3 \pm 3.9^{\mathrm{a}}$ & $105.1 \pm 2.4^{\mathrm{a}}$ & $103.9 \pm 4.3^{\mathrm{a}}$ \\
& II & $87.0 \pm 1.7$ & $94.8 \pm 3.4$ & $97.9 \pm 1.6$ \\
\hline
\end{tabular}

Note: Group I = WKY control, Group II = SHR, Group III = SHR diabetic and Group IV = SHR diabetic NaHSTreated; ${ }^{a} p<0.05$ versus WKY on respective days; ${ }^{b} p<0.05$ versus SHR on respective days; ${ }^{c} p<0.05$ versus SHR diabetic on respective days

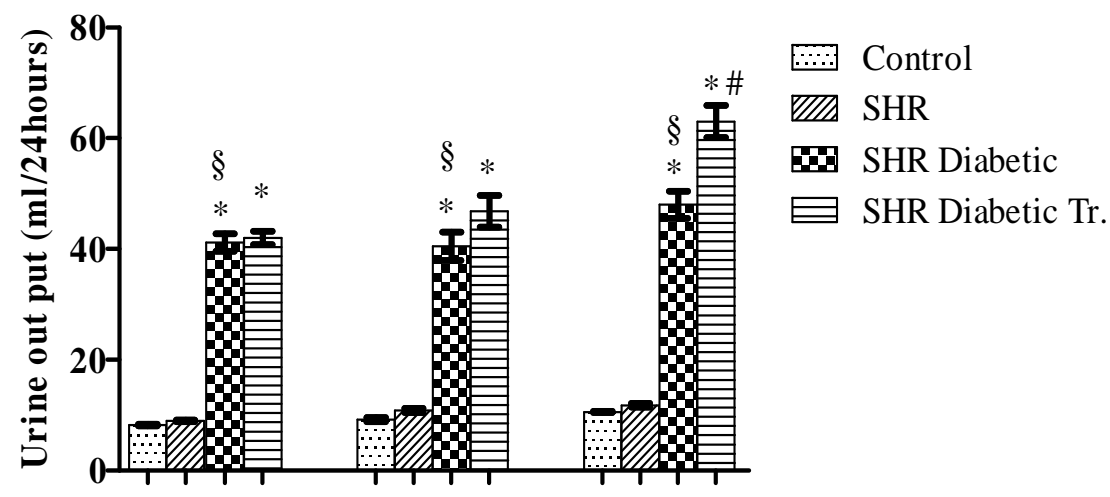
Day 0
Day 21
Day 34

Fig 1: Urine output of WKY, SHR, SHR diabetic and SHR diabetic treated groups of rats. ${ }^{*} p<0.05$ versus WKY on respective days; ${ }^{\S} p<0.05$ versus SHR on respective days; ${ }^{\sharp} p<0.05$ versus SHR diabetic on respective days 


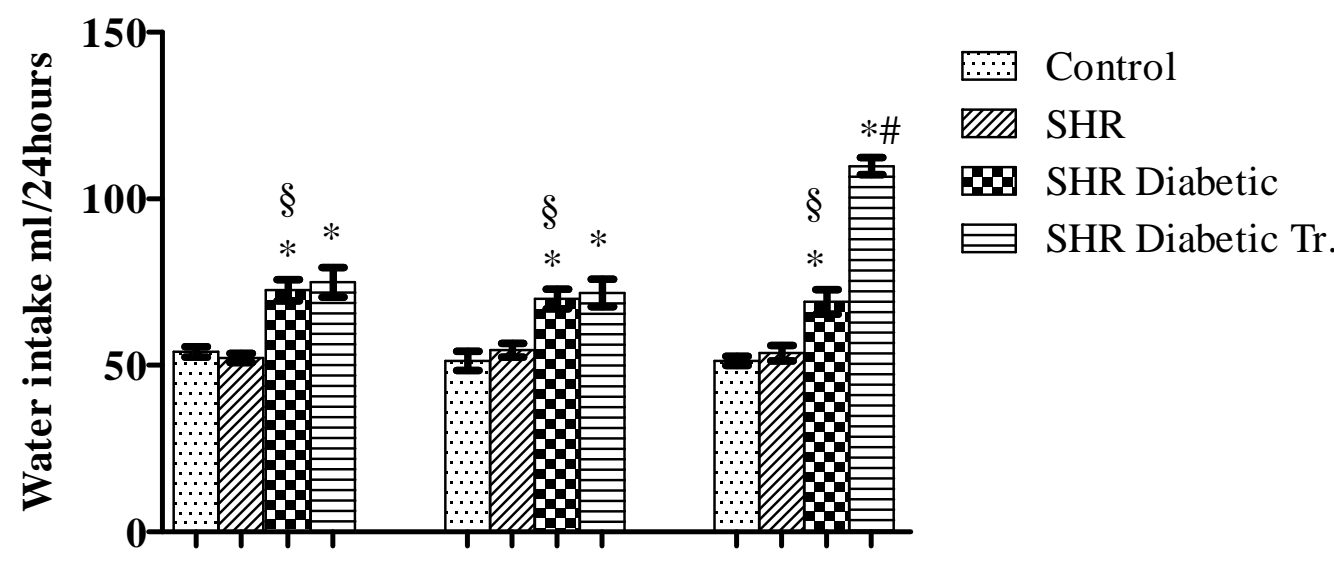

Day $0 \quad$ Day $21 \quad$ Day 34

Fig 2: Water intake of WKY, SHR, SHR diabetic and SHR diabetic treated groups of rats. ${ }^{*} p<0.05$ versus WKY on respective days; ${ }^{\S} p<0.05$ versus SHR on respective days; ${ }^{\#} p<0.05$ versus $S H R$ diabetic on respective days

\section{Effect of exogenous $\mathrm{H}_{2} \mathrm{~S}$ on mean arterial and systolic blood pressures}

It was found that the mean arterial blood pressure and systolic blood pressure of SHR, SHR diabetic and SHR diabetic NaHS-treated rats remained significantly higher on all the three observation points compared to the normotensive WKY control $(p<0.05)$. There was no significant difference in mean arterial blood pressure and systolic blood pressure between the SHR and SHR diabetic rats. It was also apparent that with NaHS treatment, the mean arterial blood pressure and systolic blood pressure of the NaHS-treated group significantly decreased on days 21 and 34 in comparison to SHR diabetic group $(p<0.05$; Table 3$)$. It was observed that plasma and urinary $\mathrm{H}_{2} \mathrm{~S}$ levels in the SHR and SHR diabetic groups of rats significantly decreased at all the three time points compared to the WKY control $(p<0.05)$. Moreover, the SHR diabetic group of rats had a significantly lower level of $\mathrm{H}_{2} \mathrm{~S}$ both in plasma and urine on day 34 compared to the SHR group $(p<0.05)$. Treatment with $\mathrm{NaHS}$ increased the plasma and urinary levels of $\mathrm{H}_{2} \mathrm{~S}$ in the SHR diabetic treated group at days 21 and 34 compared to the SHR diabetic group $(p<0.05$; Table 3).

\section{Effect exogenous $\mathrm{H}_{2} \mathrm{~S}$ on plasma sodium concentration}

It was observed that there was no significant difference of plasma sodium concentration of SHR group in comparison to WKY control group throughout the study period. On the other hand it was found that SHR diabetic group showed higher levels of plasma sodium concentration on all the three points of observation as compared to SHR control group $(p<0.05)$. With $\mathrm{NaHS}$ treatment the plasma sodium concentration of treated group started to decrease and reached the significant level on days 21 and 34 i.e. (146.0 \pm 1.4 vs. $158.0 \pm 3.4 \mathrm{mmol} / \mathrm{L})$ and $(139.0 \pm 2.0$ vs. $163.0 \pm 3.0 \mathrm{mmol} / \mathrm{L})$ respectively $(p<0.05$; Figure 3).

\section{Effect of exogenous $\mathrm{H}_{2} \mathrm{~S}$ on absolute sodium excretion}

It was noticed that SHR group of rats showed decreased levels of absolute sodium excretion in comparison to WKY controls on day $0(p<0.05)$. However, as the study progressed, there was no significant difference of absolute sodium excretion when compared to WKY control group $(p>0.05)$. On the other hand with the induction of diabetes the SHR diabetic group of rats had increased values of absolute sodium excretion compared to SHR controls throughout the study (all $p<0.05$ ). Treatment with NaHS increased the absolute sodium excretion on days 21 and 34 in SHR diabetic treated group compared to SHR diabetic untreated controls i.e. $(0.12 \pm 0.01$ vs. $0.08 \pm 0.01 \mathrm{mmol} / \mathrm{hour} / 100 \mathrm{~g} \mathrm{Bw})$ and $(0.18 \pm$ 0.01 vs. $0.12 \pm 0.01 \mathrm{mmol} / \mathrm{hour} / 100 \mathrm{~g} \mathrm{Bw})$ respectively $(p<0.05$; Figure 4$)$.

\section{Effect of exogenous $\mathrm{H}_{2} \mathrm{~S}$ on sodium excretion}

It was noticed that there was no significant difference in terms of fractional sodium excretion between SHR and WKY control group throughout 
Table 3: Mean arterial blood pressure, systolic blood pressure, plasma and urinary $\mathrm{H}_{2} \mathrm{~S}$ of $\mathrm{NaHS}$-treated and non treated diabetic spontaneously hypertensive rats

\begin{tabular}{|c|c|c|c|c|}
\hline \multirow[b]{2}{*}{ Parameter } & \multirow[b]{2}{*}{ Group } & \multicolumn{3}{|c|}{ Observation } \\
\hline & & Day 0 & Day 21 & Day 34 \\
\hline \multirow[t]{4}{*}{ Mean arterial BP $(\mathrm{mmhg})$} & 1 & $107.0 \pm 2.1$ & $105.00 \pm 2.7$ & $104.0 \pm 1.9$ \\
\hline & II & $146.0 \pm 2.6^{a}$ & $148.0 \pm 3.7^{\mathrm{a}}$ & $142.0 \pm 2.8^{\mathrm{a}}$ \\
\hline & III & $147.0 \pm 3.7^{\mathrm{a}}$ & $152.0 \pm 4.1^{\mathrm{a}}$ & $144.0 \pm 2.5^{\mathrm{a}}$ \\
\hline & IV & $149.0 \pm 3.6^{a}$ & $140.0 \pm 2.6^{\mathrm{ac}}$ & $131.0 \pm 2.7^{\mathrm{ac}}$ \\
\hline \multirow[t]{4}{*}{ Systolic BP (mmhg) } & 1 & $125.0 \pm 2.4$ & $122.0 \pm 1.9$ & $120.0 \pm 2.2$ \\
\hline & II & $165.0 \pm 3.7^{\mathrm{a}}$ & $166.0 \pm 2.8^{\mathrm{a}}$ & $160.0 \pm 2.5^{\mathrm{a}}$ \\
\hline & III & $166.0 \pm 2.9^{a}$ & $171.0 \pm 2.6^{\mathrm{a}}$ & $162.0 \pm 2.0^{\mathrm{a}}$ \\
\hline & IV & $166.0 \pm 2.1^{\mathrm{a}}$ & $158.0 \pm 2.5^{\mathrm{ac}}$ & $148.0 \pm 3.2^{\mathrm{a} c}$ \\
\hline \multirow[t]{3}{*}{ Plasma $\mathrm{H}_{2} \mathrm{~S}(\mu \mathrm{M})$} & 1 & $41.1 \pm 1.5$ & $40.6 \pm 2.1$ & $43.2 \pm 2.6$ \\
\hline & II & $\begin{array}{l}26.8 \pm 1.0^{\mathrm{a}} \\
27.6 \pm 1.0^{\mathrm{a}}\end{array}$ & $\begin{array}{l}25.3 \pm 1.8^{\mathrm{a}} \\
25.8 \pm 1.0^{\mathrm{a}}\end{array}$ & $\begin{array}{l}23.3 \pm 0.9^{\mathrm{a}} \\
17.0 \pm 0.5^{\mathrm{a}}\end{array}$ \\
\hline & IV & $27.8 \pm 1.1^{\mathrm{a}}$ & $35.6 \pm 1.9^{c}$ & $39.0 \pm 1.7^{c}$ \\
\hline \multirow[t]{4}{*}{ Urinary $\mathrm{H}_{2} \mathrm{~S}(\mu \mathrm{M})$} & 1 & $34.3 \pm 1.0$ & $37.8 \pm 2.4$ & $37.5 \pm 3.3$ \\
\hline & II & $23.9 \pm 0.5^{a}$ & $23.3 \pm 0.7^{a}$ & $21.9 \pm 0.5^{\mathrm{a}}$ \\
\hline & III & $24.3 \pm 0.4^{\mathrm{a}}$ & $22.3 \pm 0.8^{\mathrm{a}}$ & $15.0 \pm 0.5^{\mathrm{a} b}$ \\
\hline & IV & $23.3 \pm 1.8^{\mathrm{a}}$ & $31.4 \pm 1.2^{c}$ & $35.4 \pm 1.6^{\mathrm{C}}$ \\
\hline
\end{tabular}

Note: Group I = WKY control, Group II = SHR, Group III = SHR diabetic and Group IV = SHR diabetic NaHStreated; ${ }^{a} p<0.05$ versus $W K Y$ on respective days; ${ }^{b} p<0.05$ versus SHR on respective days; ${ }^{c} p<0.05$ versus SHR diabetic on respective days

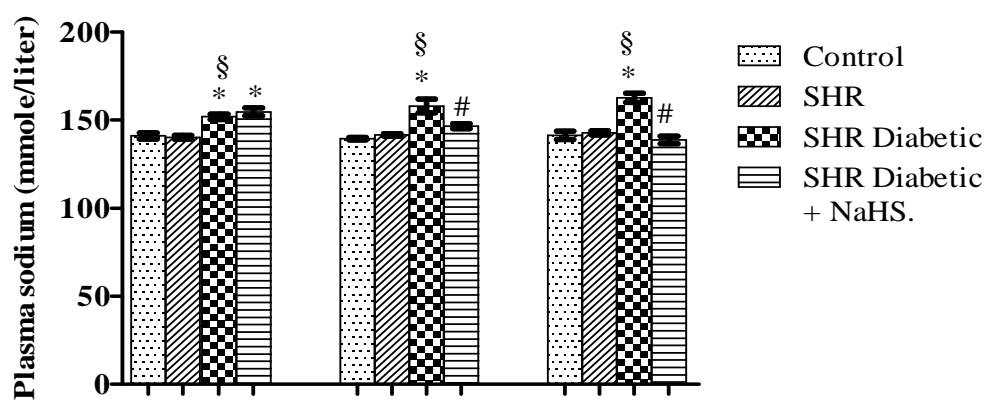

Day 0 Day $21 \quad$ Day 34

Fig 3: Plasma sodium of WKY, SHR, SHR diabetic and SHR diabetic treated groups of rats. ${ }^{*} P<0.05$ versus WKY on respective days; ${ }^{\S} p<0.05$ versus SHR on respective days; ${ }^{*} p<0.05$ versus SHR diabetic on respective days

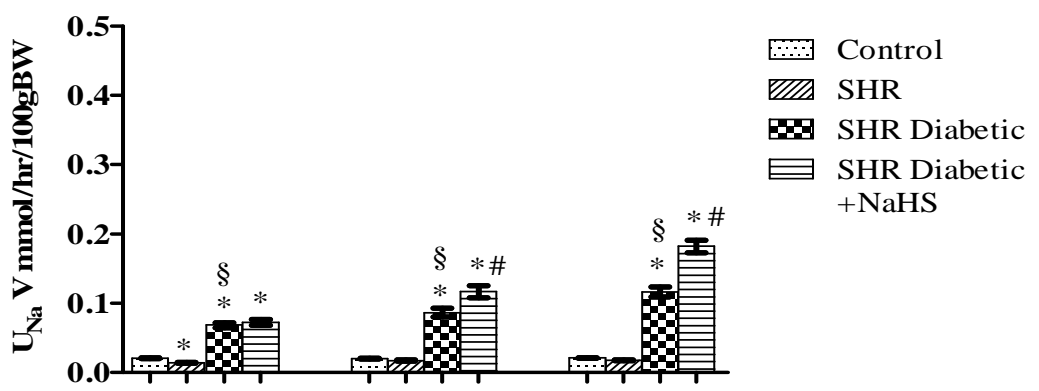

Day 0 Day $21 \quad$ Day 34

Fig 4: Absolute sodium excretion of WKY, SHR, SHR diabetic and SHR diabetic treated groups of rats. ${ }^{*} P<0.05$ versus $W K Y$ on respective days; ${ }^{\S} P<0.05$ versus $S H R$ on respective days; ${ }^{\#} P<0.05$ versus SHR diabetic on respective days 


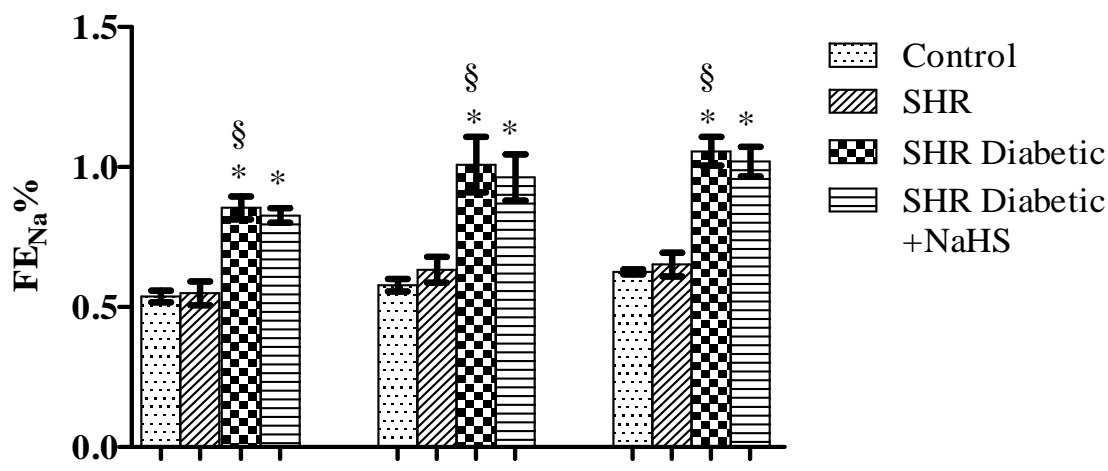

Day $0 \quad$ Day $21 \quad$ Day 34

Fig 5: Fractional sodium excretion of WKY, SHR, SHR diabetic and SHR diabetic treated groups of rats. $p<$ 0.05 versus WKY on respective days; ${ }^{s} p<0.05$ versus SHR on respective days; ${ }^{*} p<0.05$ versus SHR diabetic on respective days

the study period. Additionally, it was also observed that SHR diabetic and SHR diabetic treated groups exhibited higher values of fractional sodium excretion on all the three points of observation in comparison to WKY controls $(p$ $<0.05$ ). Moreover, SHR diabetic group had increased values of fractional excretion of sodium when compared to SHR controls on all the three points of observations $(p<0.05)$. With $\mathrm{NaHS}$ treatment, there was a trend of increased fractional sodium excretion in SHR diabetic treated rats but the values did not reach to the significant (Figure 5).

\section{DISCUSSION}

The present study investigated the possible diuretic effect of hydrogen sulfide in a combined state of hypertension and diabetes. This was done by studying the effects of supplementation of $\mathrm{H}_{2} \mathrm{~S}$ on renal sodium handling and blood pressure in spontaneously hypertensive diabetic rats. The major findings of present study were that the applied exogenous $\mathrm{H}_{2} \mathrm{~S}$ in the form of $\mathrm{NaHS}$ reduced the blood pressure, increased the $\mathrm{H}_{2} \mathrm{~S}$ levels, significantly attenuated the sodium retention, and increased the sodium and water excretion in a concomitant state of hypertension and diabetes.

Streptozotocin (STZ) has been used for many decades to produce experimental diabetes. It has been stated that a single injection of streptozotocin (STZ) could cause hyperglycemia and a decrease in body weight [12]. In the present study, the SHR rats exhibited the classical signs of diabetes mellitus i.e. hyperglycemia, polyuria and polydipsia after the streptozotocin injection. The resultant STZ induced hyperglycemia is due to the irreversible
O-glycosylation of intracellular proteins and pancreatic $\beta$-cell death [16]. Moreover, the above findings are reinforced by the significant weight loss in diabetic groups of rats. These finding are consistent with the findings that the weight loss is one of the common happening in STZ induced diabetes in rats [17]. The weight loss in STZ induced diabetes can be elucidated in terms of basic aspects of impaired carbohydrate metabolism. The lack of insulin results in decreased glucose transport across the cell membrane especially in liver, muscles and adipose tissue. Despite the NaHS treatment, the blood glucose level remained high throughout the study period suggesting that exogenously administered $\mathrm{H}_{2} \mathrm{~S}$ did not have any significant anti-diabetic effect. Moreover, the NaHS-treated rats continued to lose weight parallel to the diabetic group indicative of no effect on body weight by the exogenous $\mathrm{H}_{2} \mathrm{~S}$.

Polyuria and polydipsia is the important indicator of diabetic state. The observed polyuria and polydipsia in the present study were in agreement with several other studies and that in our laboratory [18]. These findings can be explained on the basis of hyperglycemia, defective reabsorption of glucose by proximal renal tubules, glucosuria and increase in the osmotic pressure that resulted in increased urine production. Subsequently loss in body volume is replaced by intracellular water that leads to dehydration and increased thirst [19] which accounts for polydipsia in this study. Alternatively, the polyuria in SHR diabetic can also results from the hyperactivity of $\alpha 1$ adrenoreceptors on glomerular efferent or systemic resistance arterioles to circulating levels of noradrenaline in vascular dysfunction and results in vascular hyperfiltration [20]. On the 
contrary, it was noticed that in the hypertensive diabetic rats treated with exogenous $\mathrm{H}_{2} \mathrm{~S}$, the urine output increased significantly as compared to their non treated counterparts. The observation of an increased urine volume with $\mathrm{NaHS}$ treatment can possibly be explained on the basis of a natriuresis, as seen in the present study, such that the water passively followed the sodium which resulted in an increase in urine output. The substantiation of the present study would support the view that the exogenous $\mathrm{H}_{2} \mathrm{~S}$ causes the increased water excretion even in a setting of increased activity of RAAS, commonly linked to the pathophysiology of hypertension contaminant with diabetes [21]. However, the above suggestion requires further exploration.

In the present study, it was also found that plasma and urinary levels of $\mathrm{H}_{2} \mathrm{~S}$ in SHR diabetic group significantly decreased without changes in blood pressure as compared to SHR control group as the duration of diabetes increased. An earlier study which addressed the involvement of $\mathrm{H}_{2} \mathrm{~S}$ in vascular dysfunction in non obese diabetic mice (NOD) reported the progressive reduction of plasma $\mathrm{H}_{2} \mathrm{~S}$ levels and reduced stimulated production of $\mathrm{H}_{2} \mathrm{~S}$ in the presence of L-cysteine substrate paralleled to the severity and duration of diabetes [22]. Hence, these previous suggestions support our present finding of decreased plasma and urinary $\mathrm{H}_{2} \mathrm{~S}$ in SHR diabetic rats and also concur with an earlier study [23]. The decreased plasma and urinary $\mathrm{H}_{2} \mathrm{~S}$ levels in present setting can be explained on the basis endothelial dysfunction that is a common occurrence in diabetes [24]. Moreover, treating the SHR diabetic rats with NaHS, a donor of exogenous $\mathrm{H}_{2} \mathrm{~S}$, increased plasma and urinary $\mathrm{H}_{2} \mathrm{~S}$ levels in SHR treated group compared to SHR diabetic control. This may be explained on the basis of earlier findings that exogenous administration of NaHS possibly upregulates CSE enzyme activity resulting in increased endogenous $\mathrm{H}_{2} \mathrm{~S}$ production [25]. However the quantification of CSE mRNA by polymerase chain reaction (PCR) should be done in order to comment in particular on the down and up regulation of $\mathrm{CSE} / \mathrm{H}_{2} \mathrm{~S}$ system, but it is beyond the scope of present study. Alternatively, the increased plasma and urinary $\mathrm{H}_{2} \mathrm{~S}$ levels in SHR diabetic-NaHS treated rats suggests that exogenous $\mathrm{H}_{2} \mathrm{~S}$ might have enhanced endothelial function being a reducing agent through augmenting the antioxidant defense mechanism [26]. Nevertheless, the above hypothesis warrants further certification.

It has been reported that the abnormalities in sodium reabsorption at the level of kidney have been linked to essential hypertension and co existence of diabetes further aggravates the disturbed sodium handling by kidney [27]. The results obtained from present study showed that with the induction and progression of diabetes, the SHR diabetic group exhibited higher plasma sodium levels, absolute sodium excretion and fractional excretion of sodium as compared to SHR group. In a previous study which has used an experimental design identical to this study, SHR-STZ model, a similar increase in plasma sodium level, absolute sodium excretion and fractional excretion of sodium has been reported [16]. These results hence support our present observations on the existence of renal impairment in terms of sodium handling. It has been suggested that the increase in the plasma sodium levels in SHR diabetic rats may be due to the diabetic induced hypertrophy of renal tubules resulted in amplified sodium reabsorption [28]. The possible mechanism of sodium retention includes the enhanced glomerular filtration of glucose that leads to an increased proximal tubular sodium glucose counter-transport and an extra-vascular shift of fluid with sodium [16]. Moreover, the observed changes in sodium handling can further be explained in terms of an increase in the GFR, a common occurrence in early stage of diabetes, can linked to the net increase in filtered and reabsorbed sodium probably due to the over activity of renal $\mathrm{Na}^{+} / \mathrm{K}^{+}$ATPase [29].

In the present study it was observed that treating the diabetic hypertensive rats with NaHS, a donor of exogenous $\mathrm{H}_{2} \mathrm{~S}$, reduced the systolic and mean arterial blood pressure. This may be explained on the basis of earlier findings that exogenous $\mathrm{H}_{2} \mathrm{~S}$ relaxes vascular smooth muscle cells through the opening of KATP [2]. Moreover, administration of exogenous $\mathrm{H}_{2} \mathrm{~S}$ resulted in plasma sodium concentration of treated rats to decrease but absolute urinary sodium excretion to increase significantly compared to SHR diabetic controls and concurs with an earlier study [5]. However Xia et al conducted the experiments in normotensive non diabetic rats. Contrary to that, we used SHR diabetic model which is commonly associated to increased activity of renal $\mathrm{Na}^{+} / \mathrm{K}^{+}$-ATPase [29]. The decrease in plasma sodium levels with $\mathrm{NaHS}$ treatment in this experimental study suggests that exogenous $\mathrm{H}_{2} \mathrm{~S}$ helps in reducing the sodium retention in SHR diabetic by increasing the urinary sodium excretion in a state of $\mathrm{Na}^{+} / \mathrm{K}^{+}$ATPase hyperactivity. This might be due to the already known fact that exogenous $\mathrm{H}_{2} \mathrm{~S}$ in the form of NaHS, more likely inhibits the renal $\mathrm{Na}^{+} / \mathrm{K}^{+}-2 \mathrm{Cl}$ co-transport mechanism and renal $\mathrm{Na}^{+} / \mathrm{K}^{+}$-ATPase activity [5]. The resultant decrease in blood pressure and plasma sodium 
and increased urinary absolute sodium excretion by the exogenously administered $\mathrm{H}_{2} \mathrm{~S}$ in SHR diabetic treated group is strongly suggestive that an increased natriuresis might be a contributory factor in reducing the blood pressure in SHR diabetic rats. However, the proposed diuretic action of $\mathrm{H}_{2} \mathrm{~S}$ needs to be further investigated.

\section{CONCLUSION}

The results obtained from this study suggest that exogenously administered $\mathrm{H}_{2} \mathrm{~S}$ in the form of NaHS reduces blood pressure and increases water and sodium excretion in SHR diabetic rats. On the basis of results obtained, a possible diuretic action of exogenous $\mathrm{H}_{2} \mathrm{~S}$ is suggested in addition to its well known vasodilator effect. These findings have important implication for the use of hydrogen sulphide as a diuretic molecule in the management of experimental hypertension combined with diabetes.

\section{ACKNOWLEDGEMENT}

The authors acknowledge the Fundamental Research Grant No. 203/PFARMASI/6711217 provided by the Ministry of Science Technology and Innovation (MOSTI), Government of Malaysia to conduct this study.

\section{REFERENCES}

1. Stipanuk MH, Beck PW. Characterization of the enzymic capacity for cysteine desulphhydration in liver and kidney of the rat. Biochem J. 1982; 206: 267-277.

2. Zhao $W$, Zhang J, Lu Y, Wang $R$. The vasorelaxant effect of $\mathrm{H}_{2} \mathrm{~S}$ as a novel endogenous gaseous KATP channel opener. EMBO J. 2001; 20: 6008-6016.

3. Ali MY, Ping $C Y$, Mok $Y$. Regulation of vascular nitric oxide in vitro and in vivo; a new role for endogenous hydrogen sulphide? Br J Pharmacol. 2006; 149: 625634.

4. Zhao W, Wang R. $\mathrm{H}_{2} \mathrm{~S}$-induced vasorelaxation and underlying cellular and molecular mechanisms. Am J Physiol Heart Circ Physiol. 2002; 283: H474-H480.

5. Xia M, Chen L, Muh RW, Li PL, Li N. Production and actions of hydrogen sulfide, a novel gaseous bioactive substance, in the kidneys. J Pharmacol Exp Ther. 2009; 329: 1056-1062.

6. Rettig $R$. Does the kidney play a role in the aetiology of primary hypertension? Evidence from renal transplantation studies in rats and humans. J Hum Hypertens. 1993; 7: 177-180.

7. Leaf A, Cotran RS. Renal pathophysiology: Oxford University Press, USA; 1985.

8. Tesch GH, Allen TJ. Rodent models of streptozotocin induced diabetic nephropathy (Methods in Renal Research). Nephrology. 2007; 12: 261-266.
9. Ogihara $T$, Asano $T$, Ando $K$, Chiba $Y$, Sakoda $H$, Anai $M$, Shojima $N$, Ono $H$, Onishi $Y$, Fujishiro $M$ et al. Angiotensin II-Induced insulin resistance is associated with enhanced insulin signaling. Hypertension. 2002; 40: 872-879.

10. Sowers JR. Insulin resistance and hypertension. Am J Physiol Heart Circ Physiol. 2004; 286: H1597-H1602.

11. Ramesh B, Pugalendi KV. Antioxidant role of Umbelliferone in STZ-diabetic rats. Life Sci. 2006; 79: 306-310.

12. Anand Swarup KR, Sattar MA, Abdullah NA, Abdulla MH, Salman IM, Rathore HA \& Johns EJ. Effect of dragon fruit extract on oxidative stress and aortic stiffness in streptozotocin-induced diabetes in rats. Pharmacog Res. 2010; 2: 31-35.

13. Zhong GZ, Chen FR, Cheng YQ, Tang CS, Du JB. The role of hydrogen sulfide generation in the pathogenesis of hypertension in rats induced by inhibition of nitric oxide synthase. J Hypertens. 2003; 21: 1879-1875.

14. Suckow MA, Weisbroth SH, Franklin CL. The Laboratory Rat, 2nd ed. Elsevier Academic Press 2006. P. 655. San Diego, $C A$.

15. Ahmad FD, Sattar MA, Rathore HA, Abdullah MH, Tan S, Abrahim ZO, Abdullah NA \& Johns EJ. Exogenous hydrogen sulfide $\left(\mathrm{H}_{2} \mathrm{~S}\right)$ improves the endothelial and renal excretory functions in streptozotocin induced WKY diabetic rats. IJPSR. 2012; 3(1): 101-110.

16. Lee TN, Alborn WE, Knierman MD, Konrad RJ. The diabetogenic antibiotic streptozotocin modifies the tryptic digest pattern for peptides of the enzyme $O$ GlcNAc-selective $\mathrm{N}$-acetyl-[beta]-d-glucosaminidase that contain amino acid residues essential for enzymatic activity. Biochem Pharmacol. 2006; 72: 710-718.

17. Usui H, Shikata K, Matsuda M, Okada S, Ogawa D, Yamashita T, Hida K, Satoh M, Wada J, Makino H. HMG CoA reductase inhibitor ameliorates diabetic nephropathy by its pleiotropic effects in rats. Nephrol Dial Transplant. 2003; 18: 265-272.

18. Armenia A, Munavvar AS, Abdullah NA, Helmi A, Johns EJ. The contribution of adrenoceptor subtype (s) in the renal vasculature of diabetic spontaneously hypertensive rats. Br J Pharmacol. 2004; 142: 719726.

19. Guthrie RA, Guthrie DW. Pathophysiology of diabetes mellitus. Crit Care Nurs Q. 2004; 27: 113-125.

20. Bodmer CW, Patrick AW, How TV, Williams G. Exaggerated sensitivity to NE-induced vasoconstriction in IDDM patients with microalbuminuria. Possible etiology and diagnostic implications. Diabetes. 1992; 41: 209-214.

21. Arima $S \&$ Ito $S$. The mechanisms underlying altered vascular resistance of glomerular afferent and efferent arterioles in diabetic nephropathy. Nephrol Dial Transplant. 2003; 18: 1966-1969.

22. Brancaleone V, Roviezzo F, Vellecco V, De Gruttola $L$, Bucci M, Cirino G. Biosynthesis of $\mathrm{H}_{2} \mathrm{~S}$ is impaired in

Trop J Pharm Res, November 2014; 13(11):1875 
non obese diabetic (NOD) mice. Br J Pharmacol. 2008; 155: 673-680.

23. Jain SK, Bull R, Rains JL, Bass PF, Levine SN, Reddy S, McVie R, Bocchini JA. Low levels of hydrogen sulfide in the blood of diabetes patients and streptozotocintreated rats causes vascular inflammation? Antioxid Redox Signal. 2010; 12: 1333-1337.

24. Wong WT, Wong SL, Tian XY, Huang Y. Endothelial Dysfunction: The Common Consequence in Diabetes and Hypertension. J Cardiovasc Pharmacol. 2010; 55: 300-307.

25. Chunyu $Z$, Junbao $D$, Dingfang $B$, Hui $Y$, Xiuying $T$, Chaoshu $T$. The regulatory effect of hydrogen sulfide on hypoxic pulmonary hypertension in rats. Biochem Biophys Res Commun. 2003; 302: 810-816.
26. Kimura $Y$, Kimura $H$. Hydrogen sulfide protects neurons from oxidative stress. The FASEB J. 2004; 18: 11651167.

27. Feldt-Rasmussen B, Mathiesen ER, Deckert T, Giese J, Christensen NJ, Bent-Hansen L, Nielsen MD. Central role for sodium in the pathogenesis of blood pressure changes independent of angiotensin, aldosterone and catecholamines in type 1 (insulin-dependent) diabetes mellitus. Diabetologia. 1987; 30: 610-617.

28. Chen S, Wolf G, Ziyadeh FN. The renin-angiotensin system in diabetic nephropathy. Contrib Nephrol. 2001; 212-221.

29. Wald H, Popovtzer MM. The effect of streptozotocininduced diabetes mellitus on urinary excretion of sodium and renal $\mathrm{Na}+-\mathrm{K}_{+}-\mathrm{ATP}$ ase activity. Pflugers Arch. 1984; 401: 97-100. 